\title{
AVALIAÇÃO DA QUALIDADE MICROBIOLÓGICA DE ÁGUA SUBTERRÂNEA PROVENIENTE DE POÇOS DA REGIÃO METROPOLITANA DE FORTALEZA, CEARÁ
}

\author{
Antonia Diana Alves Bezerra ${ }^{1}$, Raianna de Oliveira Araujo ${ }^{1}$, Francisco Gabriel \\ Dias Mota Araújo ${ }^{1}$, Elcivania Rodrigues Nogueira ${ }^{2}$, Maíra Gadelha Alves Brandão ${ }^{3}$, \\ Lydia DAYANNE Maia PANTOJA ${ }^{1}$ \\ ${ }^{1}$ Universidade Estadual do Ceará - UECE \\ ${ }^{2}$ Universidade Federal do Ceará - UFC \\ ${ }^{3}$ Superintendência Estadual do Meio Ambiente - SEMACE \\ <diannabezerra13@yahoo.com.br><raianna.araujo@gmail.com><gabriel.diasmota@hotmail.com> \\ <elcivania.lu@gmail.com><maira.brandao@semace.ce.gov.br><lydia.pantoja@uece.br> \\ DOI: <https://doi.org/10.21439/conexoes.v14i2.1288>
}

\begin{abstract}
Resumo. O abastecimento público com água de qualidade é uma medida essencial à saúde, uma vez que a água pode atuar como veículo de agentes patogênicos oriundos de fezes humanas e animais. Uma das formas de identificação de tais contaminações se dá a partir do monitoramento da presença de coliformes termotolerantes que é utilizada como padrão microbiológico preconizado pela Portaria 2.914/2011 do Ministério da Saúde, este estabelece como própria para consumo humano a água ausente de coliformes termotolerantes em $100 \mathrm{~mL}$ da amostra. Desta maneira o objetivo deste estudo foi avaliar a qualidade microbiológica de água subterrânea proveniente de poços da Região Metropolitana de Fortaleza-CE. Para tanto foram analisadas 44 amostras oriundas das cidades de Fortaleza, Aquiraz, Horizonte, São Gonçalo do Amarante, Maracanaú, Pindoretama, Eusébio e Caucaia - CE. As amostras coletadas foram analisadas por profissionais do laboratório da Superintendência Estadual do Meio Ambiente - SEMACE, que adotaram a Técnica dos Tubos Múltiplos com meio de cultura A-1. Das 44 amostras analisadas 40,9\% foram positivas para coliformes termotolerantes, estando assim em desacordo com o padrão estabelecido pela legislação nacional em vigor. O consumo de água fora do padrão de potabilidade põe em risco a saúde da população, desta forma os resultados obtidos alertam para a necessidade de monitoramento das águas subterrâneas da Região Metropolitana de Fortaleza - CE, como medida preventiva contra doenças de veiculação hídrica.
\end{abstract}

Palavras-chaves: Água subterrânea. Qualidade da água. Coliformes termotolerantes.

Abstract. Public supply of water with good quality is essential to human health, since water can act as a vehicle for pathogenic agents from pollution, including human and animal feces. One of the ways to identify this type of contamination is by monitoring the presence of thermotolerant coliforms, an organism used as a microbiological standard, as determined in Brazil by Edict 2.914/2011 from the Ministry of Health, which establishes that water fit for human consumption must be free of thermotolerant coliforms in each sample of $100 \mathrm{~mL}$. The objective of this study was to evaluate the microbiological quality of groundwater from wells in the metropolitan region of Fortaleza, capital of Ceará. For this purpose, 44 samples were analyzed, from the cities of Fortaleza, Aquiraz, Horizonte, São Gonçalo do Amarante, Maracanaú, Pindoretama, Eusébio and Caucaia. The samples were analyzed by laboratory staff of the State Environmental Office (SEMACE), using the multiple-tube technique with A-1 culture medium. Of the 44 samples analyzed, $40,9 \%$ were positive for the presence of thermotolerant coliforms and thus not in conformity with the regulatory standard. Consumption of water that does not meet the potability standard poses a risk to human health, so the results obtained should serve as an alert to the need to monitor groundwater in the Fortaleza metropolitan area to prevent the spread of waterborne diseases.

Keywords: Groundwater. Water quality. Thermotolerant coliforms. 


\section{INTRODUÇÃO}

A água é um elemento essencial à vida e sua qualidade é uma importante medida de proteção à saúde e de prevenção de doenças (BRASIL, 2015). É a partir da ingestão, a qual é considerada o mecanismo de transmissão de doenças mais citado e que possui relação direta com a qualidade da água, que um indivíduo sadio pode entrar em contato com componentes nocivos à saúde (BRASIL, 2006).

Dependendo do componente nocivo as doenças originárias da má qualidade da água podem ser classificadas em doenças de origem hídrica, quando os componentes nocivos presentes na água são substâncias químicas como, por exemplo, o íon nitrato e de doenças de transmissão hídrica quando a água atua como veículo de agentes patogênicos tais como bactérias, fungos, vírus, protozoários e helmintos (Baptista Neto; WALLNERKERSANACH; PATCHINEELAM, 2008). No caso de doenças de transmissão hídrica as principais patologias são: amebíase, giardíase, gastroenterite, febre tifoide e paratifoide, hepatite infecciosa e cólera (ARAúJO et al., 2013), sendo os surtos de tais patologias considerados evitáveis (LIBâNEO, 2016). Desta forma o acesso à água tratada e esgotamento sanitário são importantes medidas que evitam ou minimizam os casos de doenças de transmissão hídrica (DUARTE; BARATELLA; PAIVA, 2015).

Estimativas do Centro de Controle e Prevenção de Doenças (CDC) relatam que as doenças de transmissão hídrica no mundo sejam responsáveis por mais de $2 \mathrm{mi}-$ lhões de mortes a cada ano, sendo considerado como principal grupo de risco crianças com menos de cinco anos (TORTORA; FUNKE; CASE, 2016). No Brasil, entre os anos de 2003 e 2013 houve redução na taxa de internações por diarreia, chegando a uma redução de 45,37\% (BRASIL, 2015). No estado do Ceará de acordo com o boletim epidemiológico emitido pela Secretária de Saúde do Estado, 120.113 casos de doença diarréica aguda foram notificados até a $12^{\mathrm{a}}$ semana epidemiológica do ano de $2016(03 / 01 / 2016$ a 26/03/2016), havendo um aumento de 57,4\% no número de notificações em relação ao ano de 2015 (CEARá, 2016b). Ainda segundo o boletim os casos de doenças diarréicas agudas no referido ano foram maior que a média de casos dos últimos 10 anos. Os agentes patogênicos presentes na água que acometem à saúde humana são na maioria das vezes oriundos de contaminação fecal (BLACK, 2002). Para a detecção de tais agentes patogênicos na água, se convencionou a utilização dos chamados organismos indicadores de contaminação fecal, estes quando presentes indicam a conta- minação por fezes humana ou animal, representando a potencial possibilidade de existência de agentes patogênicos (BRASIL, 2006).

As bactérias do grupo coliforme são os principais organismos indicadores de contaminação fecal frequentemente utilizados (Von Sperling, 2014), isso porque além de fazerem parte da composição de fezes humana e animal, apresentam características como: fácil detecção e quantificação por técnicas economicamente viáveis, suas concentrações estão diretamente relacionadas com o nível de contaminação, possuem tempo de sobrevivência maior na água que os agentes patogênicos, são menos exigentes em termos nutricionais, não possuem capacidade de multiplicação no meio aquático e são mais resistentes a agentes tensoativos e desinfetantes (BRASIL, 2013).

De acordo com Libâneo (2016) não é natural a ocorrência de agentes patogênicos em água de origem subterrânea e quando isso ocorre é indicativo de alguma fonte de contaminação. Ainda segundo o autor, tais fontes são a percolação por fossas, lixões ou aterros sanitários, lagoas de estabilização e a dispersão de esgotos no solo.

Todo cidadão tem o direito ao consumo de água potável, ausente de agentes patogênicos e de substâncias químicas que acarretam danos à saúde (ZERWES et al., 2015). No Brasil, a Portaria 2.914/2011 do Ministério da Saúde estabelece os procedimentos de controle e de vigilância da qualidade da água bem como o padrão de potabilidade para consumo humano (BRASIL, 2011).

No que tange, ao padrão microbiológico, a Portaria citada estabelece que para a água estar própria para consumo humano é necessário à ausência de coliformes termotolerantes em $100 \mathrm{~mL}$ da amostra. Os coliformes termotolerantes são um subgrupo de bactérias que está inserido no grupo coliforme, tal subgrupo é caracterizado pela capacidade de fermentar a lactose gerando a produção de gás no prazo de 24 horas a $44,5{ }^{\circ} \mathrm{C} \pm 0,2$ ${ }^{\circ} \mathrm{C}$ em meios de cultura contendo sais biliares ou outros agentes tensoativos com propriedades inibidoras similares (SOUTO et al., 2015).

Uma vez que a presença de agentes patogênicos em água destinada ao abastecimento humano acarreta sérios danos à saúde pública, o presente estudo objetivou avaliar a qualidade microbiológica de água subterrânea proveniente de poços da Região Metropolitana de Fortaleza, Ceará utilizando como indicador de contaminação os coliformes termotolerantes. 


\section{MATERIAIS E MÉTODOS}

Foram coletadas 44 amostras de águas subterrâneas provenientes da Região Metropolitana de Fortaleza CE, no período de 2014 a 2017. Participaram da pesquisa as cidades de Fortaleza (27 amostras), Aquiraz (8), Horizonte (3), São Gonçalo do Amarante (2), Maranacaú (1) Pindoretama (1), Eusébio (1) e Caucaia (1) (Figura 1).

Figura 1: Mapa da Região Metropolitana de Fortaleza-CE com a distribuição das cidades que tiveram águas subterrâneas amostradas para análise de Escherichia coli.

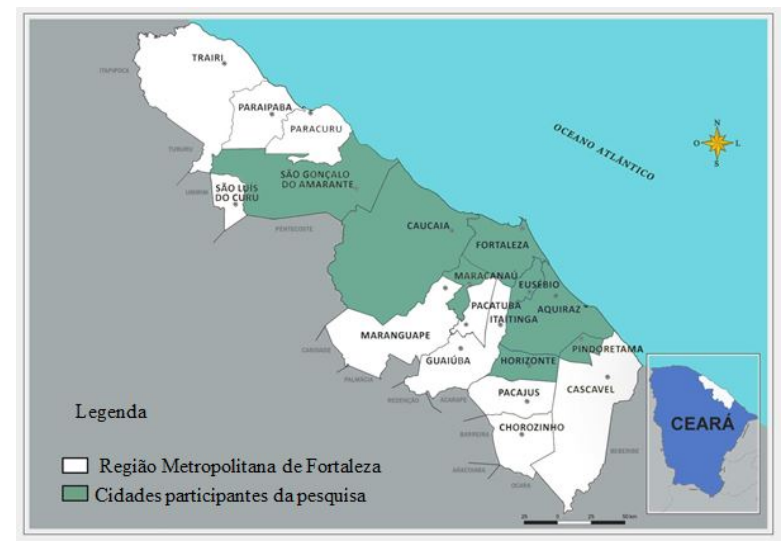

Fonte: Adaptado do Instituto de Pesquisa e Estratégia Econômica do Ceará-IPECE (2017).

As amostras foram coletadas por meio de torneiras ou canos mais próximos aos poços. Antes da realização de cada coleta, as torneiras ou canos passaram por assepsia com álcool $70 \%$ e deixou-se a água escorrer durante 3 minutos a fim de se eliminar as impurezas externas e desprezar a água acumulada na canalização. Posteriormente, em frascos de vidro borosilicato incolor com capacidade para $250 \mathrm{~mL}$, previamente esterilizados, foram coletados $200 \mathrm{~mL}$ de cada amostra. Após coletadas as amostras foram acondicionadas em caixa térmica contendo gelo e encaminhadas ao laboratório de bacteriologia da Superintendência Estadual do Meio Ambiente - Fort/CE - SEMACE e analisadas no máximo até 24 horas.

A metodologia utilizada para a determinação dos coliformes termotolerantes foi a dos tubos múltiplos utilizando o meio de cultura A-1 que permite a determinação do número mais provável (NMP) de coliformes termotolerantes em $100 \mathrm{~mL}$ da amostra. Tal metodologia que está descrita no Standard Methods for the Examination of Water and Wastewater (CLESCERI; GREENBERG; EATON, 2005), consiste em apenas uma etapa e tem duração de 24 horas.
O procedimento foi realizado da seguinte forma: para inoculação de cada amostra se utilizou três séries contendo cinco tubos cada. $\mathrm{Na} 1^{\mathrm{a}}$ série de cinco tubos o meio de cultura era de concentração dupla, ou seja, tinha o dobro da quantidade de meio de cultura A-1 necessária para um litro, já nas $2^{\mathrm{a}}$ e $3^{\mathrm{a}}$ séries de tubos a concentração era simples, pois tinha apenas a quantidade estabelecida para um litro. $\mathrm{Na} 1^{\mathrm{a}}$ série foram inoculados $10 \mathrm{~mL}$ da amostra em cada tubo, na $2^{\mathrm{a}}$ série $1 \mathrm{~mL}$ da amostra e na $3^{\mathrm{a}}$ série $1 \mathrm{~mL}$ do diluído, este consiste na diluição de $10 \mathrm{~mL}$ da amostra em $90 \pm 2 \mathrm{~mL}$ de água de diluição, desta maneira 1 $\mathrm{mL}$ do diluído consiste em $0,1 \mathrm{~mL}$ da amostra $\left(10^{-1}\right)$. Após as inoculações, as amostras foram para uma incubadora bacteriológica a temperatura de $35^{\circ} \mathrm{C} \quad 0,5^{\circ} \mathrm{C}$ permanecendo durante 3 horas e posteriormente transferidas para um banho-maria a $44,5^{\circ} \mathrm{C} \pm 0,2^{\circ} \mathrm{C}$ durante 21 horas, sendo os resultados lidos após 24 horas dada a inoculação. O resultado do teste de tubos múltiplos foi considerado positivo a partir da formação de bolha no interior do tubo de Durham, indicando assim a produção de gás resultante da fermentação realizada pelos coliformes termotolerantes (Figuras 2 e 3). Para os resultados de NMP por $100 \mathrm{~mL}$ da amostra foi utilizada tabela com limites de confiança de $95 \%$ que é indicada para inoculações de volumes $10 \mathrm{~mL}, 1 \mathrm{~mL}$ e $0,1 \mathrm{~mL}$ segundo Clesceri, Greenberg e Eaton (2005).

Figura 2: Tubos de ensaio sem formações de bolhas nos tubos de Durham, indicando resultados negativos para coliformes termotolerantes.

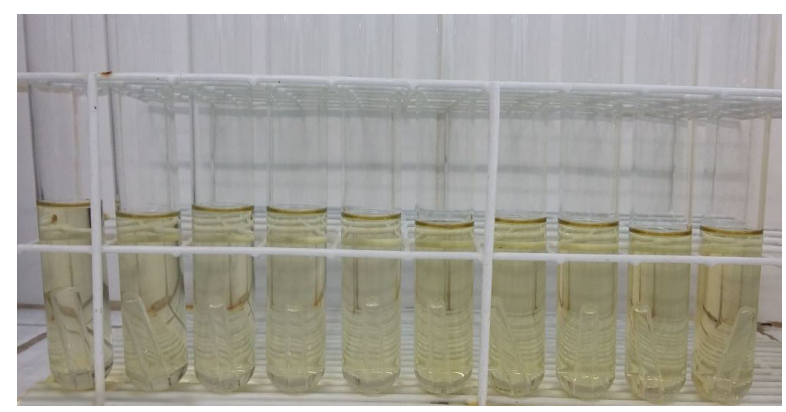

Os resultados obtidos foram comparados com o padrão de potabilidade preconizado pela Portaria $\mathrm{N}^{\mathrm{O}}$ 2.914, de 12 de dezembro de 2011 do Ministério da Saúde, que estabelece a ausência de coliformes termotolerantes em $100 \mathrm{~mL}$ da amostra.

\section{RESULTADOS E DISCUSSÕES}

Os resultados relativos à determinação do número mais provável de coliformes termotolerantes por 100 
Figura 3: Tubos de ensaio com formações de bolhas nos tubos de Durham, indicando resultados positivos para coliformes termotolerantes.

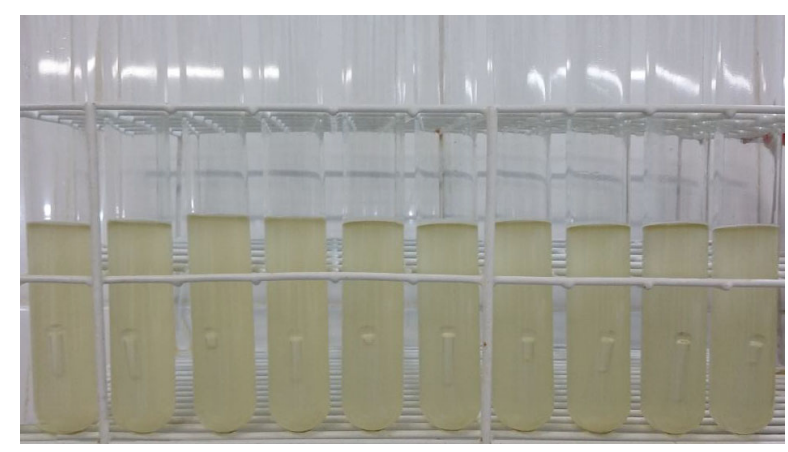

mL de amostras provenientes de águas subterrâneas da Região Metropolitana de Fortaleza - CE (Tabela 1) indicaram que das 44 amostras analisadas 18 (40,9\%) não atenderam ao padrão estabelecido pela Portaria $\mathrm{N}^{\circ}$ 2.914/2011 do Ministério da Saúde, pois se revelaram positivas quanto a presença de coliformes termotolerantes, sendo que os resultados variaram de $2 \mathrm{a} \geq 1600$ por $100 \mathrm{~mL}$ da amostra.

Das 27 amostras coletadas na cidade de Fortaleza, $40,7 \%$ (11) tiveram resultados positivos para coliformes termotolerantes, estando assim imprópria para consumo humano. Das 8 amostras coletadas em Aquiraz, confirmou-se a contaminação de $25 \%$ das amostras, enquanto que as 3 amostras da cidade de Horizonte e a amostra da cidade de Caucaia encontravam-se ausentes de contaminação. As duas amostras coletadas em São Gonçalo do Amarante estavam contaminadas, bem como as amostras das cidades de Maracanaú, Eusébio e Pindoretama, tendo sido realizadas apenas uma coleta nas referidas localidades.

Burgos et al. (2014), ao realizarem análises microbiológicas de água oriunda de poços rasos localizados na cidade de Londrina - PR objetivando avaliar a possível relação existente entre o consumo de água de tais fontes e os potenciais riscos da população em contrair doenças de veiculação hídrica, tiveram como resultados que das 168 amostras analisadas, 93 (55,3\%) apresentaram positividade para coliformes totais e E. coli. Com a pesquisa os autores concluíram que o consumo de água dos poços rasos analisados colocava em risco a saúde da população.

Na realização de mapeamento da qualidade de água subterrânea em São Franscisco de Itabapoana - RJ, Silva e Oliveira (2014) identificaram que $87,07 \%$ e $64,63 \%$ das amostras analisadas estavam respectivamente, contaminadas por coliformes totais e termoto- lerantes. Os autores do estudo apontaram como causa das contaminações a proximidade dos poços em relação as fossas.

Costa et al. (2012) em análise de 230 amostras de água subterrânea de localidades diversas do Estado Ceará obtiveram como resultado que 92 amostras (40\%) apresentaram crescimento de coliformes totais e em 28 $(12,2 \%)$ de Escherichia coli, revelando assim altos índices de contaminação microbiológica. Resultados semelhantes ao de Cajazeiras (2007) que, em seu trabalho acerca da qualidade e o uso das águas subterrâneas da Região de Crajubar - CE, verificou que a maioria dos poços analisados $(62 \%)$ apresentaram águas contaminadas por coliformes totais e termotolerantes.

Oliveira (2013) ao fazer análises bacteriológicas de águas subterrâneas de poços situados no entorno da Lagoa da Parangaba em Fortaleza - CE, obteve como resultado a presença de coliformes fecais em todas as amostras, demonstrando que estas são impróprias para o consumo humano. De acordo com o autor, o bairro Parangaba já dispõe do serviço de esgotamento sanitário, mas a utilização no passado de fossas sépticas ainda acarreta danos à qualidade da água. Outro agravante é que nem todas as residências aderiram aos serviços de saneamento básico.

Landim Neto et al. (2013) avaliando a qualidade da água subterrânea da Comunidade do Trairussu em Aquiraz nos períodos secos e chuvosos, revelaram que das 10 amostras de poços analisadas 9 (90\%) apresentaram positividade para coliformes termotolerantes no período seco e 10 (100\%) no período chuvoso. Os autores apontaram como causa da contaminação a ausência de saneamento básico na região.

Na cidade de Eusébio, Oliveira (2015) ao realizar análises qualitativas de 20 amostras de águas subterrâneas verificou que 13 amostras (65\%) apresentaram-se contaminadas por coliformes totais, embora as mesmas não apresentaram positividade para coliformes termotolerantes.

Na Região Metropolitana de Fortaleza - CE o índice de domicílios ligados à rede geral de esgoto é de $48,28 \%$, desta forma mais da metade dos domicílios ainda se utilizam de fossas sépticas ou outras formas de disposição de efluentes domésticos (IBGE, 2011 apud Ceará (2016a)), o déficit no índice de esgotamento sanitário colabora para a contaminação da água subterrânea.

\section{CONSIDERAÇÕES FINAIS}

Das 44 amostras de águas subterrâneas analisadas, 18 (40,9\%) não atenderam ao padrão microbiológico de potabilidade preconizado pela Portaria 2.914/11, pois 
AVALIAÇÃO DA QUALIDADE MICROBIOLÓGICA DE ÁGUA SUBTERRÂNEA PROVENIENTE DE POÇOS DA REGIÃO METROPOLITANA DE FORTALEZA, CEARÁ

Tabela 1: Número Mais Provável (NMP) de coliformes termotolerantes/100 mL de amostras de águas subterrâneas provenientes da Região Metropolitana de Fortaleza-CE.

\begin{tabular}{cccccc}
\hline Cidades & Amostras & NMP/100mL & Cidades & Amostras & NMP/100mL \\
\hline Fortaleza & 1 & Ausente & Fortaleza & 23 & Ausente \\
Fortaleza & 2 & 2 & Fortaleza & 24 & Ausente \\
Fortaleza & 3 & Ausente & Fortaleza & 25 & Ausente \\
Fortaleza & 4 & Ausente & Fortaleza & 26 & 14 \\
Fortaleza & 5 & Ausente & Fortaleza & 27 & \pm 1600 \\
Fortaleza & 6 & Ausente & Aquiraz & 1 & Ausente \\
Fortaleza & 7 & Ausente & Aquiraz & 2 & \pm 1600 \\
Fortaleza & 8 & 50 & Aquiraz & 3 & Ausente \\
Fortaleza & 9 & 23 & Aquiraz & 4 & Ausente \\
Fortaleza & 10 & 500 & Aquiraz & 5 & 170 \\
Fortaleza & 11 & Ausente & Aquiraz & 6 & Ausente \\
Fortaleza & 12 & Ausente & Aquiraz & 7 & Ausente \\
Fortaleza & 13 & Ausente & Aquiraz & 8 & Ausente \\
Fortaleza & 14 & 70 & Horizonte & 1 & Ausente \\
Fortaleza & 15 & 2 & Horizonte & 2 & Ausente \\
Fortaleza & 16 & 300 & Horizonte & 3 & Ausente \\
Fortaleza & 17 & Ausente & São Gonçalo do Amarante & 1 & 30 \\
Fortaleza & 18 & Ausente & São Gonçalo do Amarante & 2 & 900 \\
Fortaleza & 19 & Ausente & Maracanaú & 1 & 900 \\
Fortaleza & 20 & 8 & Pindoretama & 1 & 30 \\
Fortaleza & 21 & 13 & Eusébio & 1 & 30 \\
Fortaleza & 22 & Ausente & Caucaia & 1 & Ausente \\
\hline
\end{tabular}

se identificou a presença de coliformes termotolerantes, indicando assim a contaminação por fezes humanas e/ou animal. Logo, o consumo de tais fontes expõe a população a enfermidades de veiculação hídrica.

Para que seja garantindo o direito do cidadão ao abastecimento de água de qualidade é recomendável o monitoramento periódico da qualidade de água subterrânea, bem como o acesso a sistema de esgotamento sanitário.

\section{REFERÊNCIAS}

ARAúJO, M. F. F. D.; NASCIMENTO, V. S. F. D.; SANTANNA, E. M. E.; COSTA, I. A. S. D.; PANOSSO, R. D. F. Doenças de veiculação hídrica: conhecendo e prevenido. 1. ed. Batal, 2013.

Baptista Neto, J. A.; WALLNER-KERSANACH, M.; PATCHINEELAM, S. M. Poluição Marinha. 1. ed. Rio de Janeiro: Interciência, 2008.

BLACK, J. G. Microbiologia fundamentos e perspectivas. 4. ed. Rio de Janeiro: Guanabara Koogan, 2002.
BRASIL. Vigilância e controle da qualidade da água para consumo humano. Brasília, 2006.

BRASIL. Portaria no 2914 de 12 de dezembro de 2011. Dispõe sobre os procedimentos de controle e de vigilância da qualidade da água para consumo humano e seu padrão de potabilidade. Diário Oficial da União, Seção 1, p. 266, 16 dez. 2011. [S.1.], 2011.

BRASIL. Manual prático de análise de água. 4. ed. Brasília: FUNASA, 2013.

BRASIL. Análise de indicadores relacionados à água para consumo humano e doenças de veiculação hídrica no Brasil ano 2013, utilizando a metodologia da matriz de indicadores da Organização Mundial (OMS). Brasília, 2015.

BURGOS, T. d. N.; ALFONSO, P. A.; LIMA, N. R.; LOPES, A. M.; PELAYO, J. S. Água de consumo humano proveniente de poços rasos como fator de risco de doenças de veiculação hídrica. Rev. Ciênc. Saúde, São Luís, v. 16, n. 1, p. 34-38, 2014.

CAJAZEIRAS, C. C. A. Qualidade e uso das águas subterrâneas e a relação com doenças de veiculação 
AVALIAÇÃO DA QUALIDADE MICROBIOLÓGICA DE ÁGUA SUBTERRÂNEA PROVENIENTE DE POÇOS DA REGIÃO METROPOLITANA DE FORTALEZA, CEARÁ

\begin{abstract}
hídrica, Região de Crajubar/CE. Dissertação (Mestrado em Geologia) - Universidade Federal Do Ceará, Fortaleza, 2007. 143 f.

CEARá. Boletim Epidemiológico: Doenças diarreicas agudas. 2016. Disponível em: $<$ http://www.saude.ce.gov.br/index.php/boletins $>$. Acesso em: 13 fev. 2017.
\end{abstract}

CEARá. Perfil Básico Regional 2016. 2016. Disponível em: <http://www2.ipece.ce.gov.br/ estatistica/perfil_regional/2016/Perfil_Regional_ Grande_Fortaleza2016.pdf>. Acesso em: 20 fev. 2017.

CEARá. Ceará em Mapas. 2017. Disponível em: $<$ http://www2.ipece.ce.gov.br/atlas/capitulo1/11/125x. htm>. Acesso em: 08 jan. 2017.

CLESCERI, L. S.; GREENBERG, A. E.; EATON, A. D. Multiple-tube fermentation technique for members of the coliform group. STANDARD methods, examination of water and wastewater, v. 20, n. 1, p. 947-957, 2005.

COSTA, C. L.; LIMA, R. F. d.; COSTA, G. C.; PANTOJA, L. D. M. Avaliação da qualidade das águas subterrâneas em poços do estado do ceará, brasil. Semina: Ciências Biológicas e da Saúde, Semina: Ciências Biológicas e da Saúde, v. 33, n. 2, p. 171-180, 2012.

DUARTE, P. S. C.; BARATELLA, R.; PAIVA, A. S. As doenças de veiculação hídrica: um risco evidente. In: EDUCATIVOS, C. I. T. D. E. P. (Ed.). ENCONTRO DE PESQUISA EM EDUCAÇÃO. Uberaba: UNIUBE, 2015. v. 8, n. 3, p. 22-24.

Landim Neto, F. O.; SILVA, E. V. da; MAGALHÃES, G. B.; FILHO, N. de S. P. Avaliação da qualidade da água subterrânea em poços da comunidade do trairussu inserida no litoral oriental do ceará, brasil. Espaço Aberto, Universidade Federal do Rio de Janeiro, v. 3, n. 1, p. 173-188, 2013.

LIBâNEO, M. Fundamentos de qualidade e tratamento de água. 4. ed. Campinas: Átomo, 2016.

OLIVEIRA, M. R. B. O crescimento urbano e o risco à poluição das águas subterrâneas freáticas no entorno da Lagoa da Parangaba, Fortaleza - Ceará. Dissertação (Mestrado em Geologia) — Universidade Federal do Ceará, Fortaleza, 2013. 130 f.

OLIVEIRA, R. M. Avaliação quanti-qualitativa das águas subterrâneas do município de Eusébio
- Ceará. Dissertação (Mestrado em Geologia) Universidade Federal do Ceará, Fortaleza, 2015. 116 f.

SILVA, R. A.; OLIVEIRA, V. d. P. S. de. Mapeamento da qualidade de água subterrânea em são francisco de itabapoana - rj. In: CONGRESSO BRASILEIRO DE ÁGUAS SUBTERRÂNEAS. Belo Horizonte: ABAS, 2014. v. 18, n. 1, p. 20.

SOUTO, J. P.; LIRA, A. G. S.; FIGUEIRA, J. S.; SILVA, A. N.; SILVA, E. S. Poluição fecal da água: microorganismos indicadores. In: CONGRESSO BRASILEIRO DE GESTÃO AMBIENTAL. Porto Alegre: IBEAS, 2015. v. 6, n. 1, p. 6.

TORTORA, G. J.; FUNKE, B. R.; CASE, C. L. Microbiologia. 12. ed. São Paulo: Artmed, 2016.

Von Sperling, M. Introdução à qualidade das águas e ao tratamento de esgotos: princípios do tratamento biológico de águas residuárias. 4. ed. Belo Horizonte: UFMG, 2014.

ZERWES, C. M.; SECCHI, M. I.; CALDERAN, T. B.; BORTOLI, J. de; TONETTO, J. F.; TOLDI, M.; OLIVEIRA, E. C. de; SANTANA, E. R. R. de. Análise da qualidade da água de poços artesianos do município de imigrante, vale do taquari/rs. Ciência e Natura, Universidade Federal de Santa Maria, v. 37, n. 3, p. 651-663, 2015. 